\title{
O uso da rubrica na obra de Jorge Andrade
}

\author{
Elisabeth Azevedo
}

lém da óbvia oportunidade de se perceber como as indicações didascálicas servem para ajudar a criar o perfil dos personagens e conduzir o desenrolar do enredo da peça, a análise das rubricas pode revelar uma outra dimensão do trabalho de um dramaturgo.

Neste artigo, vai-se considerar a rubrica dentro da projeção que ela assumiu no teatro do século $\mathrm{XX}$, como reflexo da maior preocupação de autores dramáticos com os elementos da encenação que poderiam contribuir para a narrativa, ampliando o universo ficcional a ser explorado, e também conduzindo à opção pela forma épica de teatro, mais adequada à abordagem de determinados assuntos. Dentro desse contexto, é possível estudar a produção dramática do teatrólogo brasileiro Jorge Andrade como um exemplo do modo pelo qual o "espetacular" foi tomando lugar cada vez mais importante em sua obra, em comparação com o estritamente literário.

A obra de Jorge Andrade é única dentro do panorama teatral brasileiro. Nenhum outro dramaturgo criou um trabalho tão orgânico e articulado como esse autor paulista. A partir de sua proposta inicial de criar um teatro que refletisse a realidade brasileira, através de sua história e seu povo, Jorge Andrade acabou por escrever um conjunto de textos, organizados num único corpo, composto por dez peças, conhecido como o ciclo Marta, a Arvore e o Relógio (Andrade, 1970).

$\mathrm{Na}$ forma em que foi publicado, o ciclo Marta não obedece à cronologia da criação das obras que o compõem. No caso deste artigo, mais conseqüente é considerar a ordem temporal das peças, para que se possa fazer uma análise das eventuais transformações sofridas por elas. Nesse caso, também devem ser incluídos os textos que não fazem parte do ciclo Marta, mas que foram escritos na mesma época, ou posteriormente.

Em termos de análise das rubricas usadas pelo autor, a primeira constatação é de que, em função da publicação do ciclo, Jorge Andrade alterou vários trechos de suas peças. Dentre as mudanças efetuadas, encontram-se algumas que dizem respeito às rubricas.

Em primeiro lugar, no momento em que as dez peças foram agrupadas, perderam, de certa forma, parte de sua autonomia e sob um título comum (Marta, a Arvore e o Relógio) passaram a ser "capítulos" de uma obra maior, como subtítulos, ao invés de títulos isolados ${ }^{1}$. Tal mudança acentuou o caráter épico que já

Elisabeth Azevedo é doutora em dramaturgia e pesquisadora.

1 Jorge Andrade desejava que o ciclo fosse montado como um espetáculo único, durante dez dias seguidos, no que seria, sem dúvida, uma empreitada titânica, inédita até hoje. Cada peça tem também como epígrafe trechos de um mesmo poema de Carlos Drummond de Andrade, O Fazendeiro do Ar, publicado em Poesia Até Agora. 
impregnava fortemente a maior parte dos textos. O mesmo efeito foi conseguido com a inclusão de referências (intratextualidade) de fatos e personagens de uma história na outra.

Mais uma modificação com respeito às rubricas é a escolha e/ou mudança de alguns nomes de personagens. $\mathrm{O}$ uso do nome Marta, por exemplo, encarnada como protagonista apenas em As confrarias, mas que aparece em diversas peças, cria um fio condutor da obra e representa a força vital que move os personagens mais fortes, e a própria História. O mesmo processo se repete com outros nomes, cada qual carregando em si uma forte carga simbólica: Vicente (uma projeção do próprio autor), Martiniano (ancestral e descendente), Lavinia/Lúcia/Lucilia (mulheres da família), Jupira (a eterna prostituta), Joaquim (o colono e o dono de terras). Essas rubricas nominativas ${ }^{2}$, portanto, passam a apresentar uma carga metafórica maior na obra do autor do que se fossem simples nomes, escolhidos um pouco ao acaso.

Neste artigo se focalizará o uso feito pelo autor de outros tipos de rubricas, além das nominativas, no intuito de se perceber como, e se, elas se modificam com passar do tempo, e se são capazes de indicar uma linha evolutiva na obra de Jorge Andrade, bem como mudanças na concepção cênica em seus dramas. Como seria muito extenso examinar todas as peças, foram eleitas quatro, representativas dentre as 14 que o autor compôs. São elas: $A$ moratória (1954), Vereda da salvação (1957/64), As confrarias (1970) e Milagre na cela (1977).

$A$ moratória ${ }^{3}$, dos quatro dramas escolhidos, foi o primeiro sucesso de Jorge Andrade como dramaturgo. Antes havia publicado apenas $O$ telescópio - uma peça ainda bastante tradicional em termos de encenação. Já $A$ moratória trouxe ao palco brasileiro um procedimento ainda incomum para a época. Claro, antes se assistira a Vestido de noiva, de Nelson Rodrigues (com seus três planos distintos). Sabe-se que Jorge Andrade reestruturou seu texto com base em sua leitura. Evidentemente, o trabalho de Jorge não é meramente uma cópia do que foi feito por Nelson Rodrigues. Enquanto Vestido de Noiva usa a compartimentação cênica para como que suspender o tempo, instalando no palco um drama intemporal (pode ser visto como um último espasmo de consciência da protagonista, Alaíde, onde os passados, remoto e próximo, se misturam), o recorte que Jorge dá à sua peça acentua justamente o aspecto do tempo no conflito. Através do recurso de dividir o palco ao meio e apresentar lado a lado cenas diversas, mas correspondentes (como ecos), ele reforça o efeito que o tempo, a história e a vida trazem sobre os personagens e os conflitos.

Para conseguir esse jogo de falas e cenas entrecortadas e ecoadas, o autor lança mão das rubricas atributivas que devem ser entendidas como uma marcação de compasso numa partitura musical - estabelecendo um canto-contracanto. A peça não é dividida em atos ou cenas, mas em primeiro e segundo planos - de acordo com o lado da cena em que se desenrola o conflito principal.

Não é menos elaborado o aspecto visual da peça. Apesar de ainda não haver um jogo importante com as luzes e com sons (como mais tarde ocorrerá) $)^{4}$, os cenários estão impregnados de elementos simbólicos que remetem o público a uma dimensão não explícita nos diálogos, ou que reforçam esses mesmos diálogos. Tal procedimento pode, por exemplo, ser "lido" explicitamente no galho de jabuticabeira que é colocado suspenso sobre a linha divisória do

2 São quatro os tipos de rubricas (internas): nominativa/atributiva - quem fala; destinativa - para quem se fala; locativa - onde se fala e melódica - em que tom. Ver Issacharoff.

3 A segunda peça a ser composta, ocupa o terceiro lugar dentro da coletânea.

4 Ver o que acontece em Rasto Atrás. 
cenário e que simboliza um mundo, um passado que murchou, secou, mas que ainda assombra a todos com sua nostalgia.

Outros diferentes elementos também carregam forte carga simbólica: a máquina de costura, o relógio de parede, o retrato dos santos. Outro aspecto é que o plano do cenário que representa a fazenda fica mais alto - socialmente superior, esmagando o plano do presente.

Por vezes, diálogo e rubrica se misturam dando um aspecto narrativo ao texto dramático, como no caso da cena:

"Joaquim (Pausa): Onde está sua mãe?

Lucília: O senhor sabe que ela foi à igreja!

(Na palavra 'igreja' o Segundo Plano se ilumina)

Joaquim: É verdade.

(Pausa. Joaquim olha para os quadros, no Primeiro Plano, Helena aparece no Segundo Plano; encaminha-se para os quadros, ajoelha-se e começa a rezar.)

Joaquim: Era diante desses quadros que sua mãe costumava rezar lá na fazenda. (Pausa) Foram sua igreja durante trinta e cinco anos!" (Andrade, 1970, p.124-5).

A peça trabalha com esse esquema de auto-reflexos, ecos e repetiçōes para reforçar o sentimento de mudança, tanto na situação, quanto no caráter dos personagens; seja para o bem, seja para o mal.

Além das rubricas locativas (entradas e saídas são muito importantes na peça), as demais se inscrevem nas tradicionais indicações de estados psicológicos e comportamentais. Portanto, o que a peça de Jorge Andrade apresentou como inovação fixa-se através do jogo determinado nas suas rubricas. Já encontramos aqui um autor preocupado não só com o conteúdo da mensagem que queria expor, mas, igualmente, com a forma de fazê-lo.
A segunda peça escolhida é Vereda da salvaçã $0^{5}$. Nesse texto, o dramaturgo paulista abandonou o caráter épico que tinha marcado $A$ moratória e trabalhou dentro de padrões mais tradicionais da dramaturgia, tanto que o texto respeita as três unidades clássicas consagradas: ação, espaço e tempo. No interior de uma comunidade rural, no espaço de um dia, há o conflito e o desenlace do drama dos miseráveis trabalhadores em sua busca de uma vida mais digna, através de uma desesperada e alucinada fé.

Aí surge um importante exemplo daquela intratextualidade, referida anteriormente, $\mathrm{da}$ obra jorgeandradiana. Tanto nesta peça, quanto em $A$ moratória, os protagonistas têm o nome de Joaquim. Queria o autor que eles fossem as duas faces de uma mesma moeda - a moeda da história, das forças sociais poderosas, dos interesses que esmagam a quem for preciso, que enlouquecem os joaquins que não têm como combatê-las. Eles sucumbem diante da inexorabilidade da força do poder econômico e político; a uns ela alucina (o Joaquim de Vereda), a outros ela imbeciliza (o Joaquim de $A$ moratória). Portanto, a importância da escolha do nome dos personagens tem neste exemplo a sua medida e dá um sabor épico a esse texto tão próximo da tragédia, por integrá-lo num corpo maior.

Como em A moratória, Jorge Andrade trabalhou a encenação de maneira a que as referências visuais (e sonoras) fossem uma abertura esse mundo opressivo a que estão presos os colonos do sertão brasileiro. O cenário é único nos dois atos que formam a peça. No primeiro, é final de tarde, no segundo, noite fechada. O drama se dá na escuridão, no confinamento de uma comunidade fechada sobre si mesma, sem horizontes ou perspectivas. É também a escuridão da ignorância e do fanatismo que aniquilam o pouco de discernimento de que essa gente rude é capaz.

5 Quinta peça do ciclo, teve oito versões, sendo que a primeira publicação é de 1965. Foi o quarto texto a ser publicado pelo autor. 
A descrição do cenário é detalhada logo de início e impõe sua concepção ficcional aos elementos visuais que aparecerão no palco. Trata-se de uma clareira com pequenos casebres, envoltos por uma opressiva muralha de árvores.

É preciso chamar a atenção para alguns aspectos da concepção cênica de Vereda da salvação que indicam a proximidade da peça, e do restante da obra de Jorge Andrade, com o Expressionismo. Esse movimento artístico alemão, efervescente no pré e no pós-Primeira Guerra Mundial, foi um fenômeno quase tão diversificado e seminal quanto o Renascimento. Inovando em diversos aspectos as artes em geral marca, sem dúvida, a emergência do teatro contemporâneo. Tudo o que se fez em termos de teatro no século XX deve muito aos dramaturgos alemães do início deste século (e seus precursores: Strindberg, Büchner, Wedekind).

No que tange a obra jorgeandradiana, pode-se dizer que ecos dos procedimentos consagrados pelos expressionistas germânicos emergem nela. Do mesmo modo que Nelson Rodrigues apresenta certas características expressionistas, Jorge Andrade apresenta outras, diferentes, mas igualmente emblemáticas, como a marcada preocupação social, por exemplo.

Como bem analisa Eudinyr Fraga, não existe no Brasil um movimento expressionista organizado ou um autor exclusivamente expressionista. O que se dá com Nelson Rodrigues, por exemplo, é a utilização de alguns dos princípios dessa estética.

"No Brasil não houve nenhum dramaturgo, anterior a Nelson Rodrigues, que tenha sido influenciado pelo movimento. Muito menos ainda no que se refere à encenação. Claro, podem-se detectar traços evidentes na obra de Oswald de Andrade, por exemplo, mas não há o emprego sistemático de procedimentos expressionistas (...)
Parece-me que a maior parte de dramaturgia nelsonrodrigueana evidencia fortes características expressionistas. Não que fosse um expressionista na acepção estrita do termo, mas sua visão do mundo fundamenta-se nessa concepção existencial" (Fraga, 1998, p. 1989).

"Nelson Rodrigues também se preocupa com detalhes de encenação, visando desnaturalizar o mais possível o palco (...) para configurar a ação e criar a atmosfera de irrealidade exigida pelos textos" (id., ibid., p. 201).

"Vereda da salvação" é a primeira peça onde se pode notar em Jorge Andrade o uso de procedimentos que apontam para esse mesmo tipo de concepção. Veja-se, por exemplo, a descrição da clareira cercada pela muralha de árvores:

"Tem-se a impressão de que os casebres estão sufocados pela mata exuberante; é como se estivessem no fundo de um poço, tendo como única saida a clareira das copas das árvores" (Andrade, 1970, p. 233).

A imagem do homem ameaçado, diminuído e solitário, é claramente expressionista.

"Além dos casebres e da mata, vemos no círculo aberto pela mata, um céu avermelhado, no princípio; depois coberto de estrelas. (...) Os casebres são mal construidos, dando a impressão de que poderão cair de uma hora para outra".

Também na rubrica referente ao trabalho dos atores tem-se a indicação de um estilo não naturalista de representação, carregado de simbologia ${ }^{6}$ :

"Onofre, como quase todos os outros homens, é bastante magro, corpo ligeiramente curvado, braços fortes, porém um pouco deformados (...) [Dolôr] como as outras mulheres, tem os seios muito caídos e é seca de corpo. Qualquer coisas nelas indica que não são tão ve-

6 Não é à toa que a primeira montagem dessa peça, dirigida por Antunes Filho para o TBC, deu margem a que o diretor desenvolvesse um novo método de trabalho de atores, e criou enorme polêmica. 
lhas como aparentam ser. São mais estragadas pelo meio que pelo tempo" (id., ibid., p. 235).

A cena final da peça, depois de vários momentos de êxtase e agitação:

"Subitamente, ouvem-se de todos os lados, tiros e gritos. Enquanto as vozes gritam de fora e aumenta a fuzilaria, os agregados continuam rodopiando, cantando e arrancando as roupas, que voam no ar, confundindo com seus braços erguidos para o alto, numa súplica alucinada" (id., ibid., p. 279).

Além das rubricas que vão contribuindo para a criação de um clima de exasperação, culminando nessa cena final, deve-se destacar que Jorge Andrade conseguiu criar também, através dos diálogos, um mundo à parte, distanciando-se do registro naturalista e mimetizado do falar interiorano. Assim como seus personagens, a fala é rude e áspera, mas poética, evidenciando a separação entre esse mundo arcaico e o mundo cotidiano.

Com muito talento e através desses recursos, o autor conseguiu criar uma obra intrinsecamente brasileira, mas também profundamente universal.

A terceira peça eleita é As confrarias ${ }^{7}$. Nela se alia a poetização da linguagem à fragmentação da estrutura dramática, o que aproxima novamente o drama de Jorge Andrade da estética expressionista e épica. A via-crúcis de Marta remete claramente ao "drama de estaçôes", tão caro ao teatro expressionista.

Em As confrarias, Jorge Andrade usou e abusou dos recursos cênicos para ampliar o universo da trama, que, a rigor, é concentrada no tempo e no espaço. A história de Marta, que carrega seu filho morto de confraria em confraria (quatro no total) em busca de um lugar para enterrá-lo, passa-se em Minas Gerais, à época da Inconfidência Mineira, durante não mais do que um dia. Contudo, a cada parada, Marta repete um mesmo "jogo" e, como mestre de cerimônias, encena todo seu passado, e de seu filho, cobrindo um período de trinta anos.

Essa memória, que a protagonista materializa em cena, é invocada e projetada no palco através das indicações didascálicas. Assim como acontecera com $A$ moratória, dois planos temporais se entrecruzam, só que, desta vez, sem a divisão rígida de um palco fixo e mobiliado. Luz e som assumem um papel muito mais substancial, marcando as cenas vivenciadas por Marta, seu marido e seu filho. Deve-se, contudo, ter-se sempre em mente que aquilo que se vê é a versão que Marta apresenta dos fatos. Em várias ocasiões ela propositadamente foge a responder diretamente às questôes feitas pelos confrades, preferindo a via da alegoria e dos subterfúgios. Desse modo, o que se assiste como flash-backs pode bem ser também uma projeção da versão de Marta a respeito dos acontecimentos que levaram seu filho à morte.

De qualquer maneira, esta peça, juntamente com Rasto atrás (1965), O sumidouro (1969) e Milagre na cela, é a que apresenta esse lado cênico mais desenvolvido e dá a medida da importância que o autor atribuía ao aspecto espetacular em seu teatro:

"José, entre dezesseis e dezessete anos, vai sendo iluminado tentando imitar o crescimento e a morte de uma planta. À medida que é iluminado, os irmãos desaparecem" (id., ibid., p. 30).

Mais adiante:

"Marta volta-se e desaparece, rápida. Enquanto o andor sai, eleva-se o canto, desaparecendo o oratório. O cenário vai se transformando, à esquerda, numa rua tortuosa, è direita, ilumi-

7 É a peça que abre o ciclo, mas foi das últimas a serem compostas, depois de muitos anos de pesquisas, e publicada em 1970. 
na-se outro consistório, onde está reunida, em grande preparação, a irmandade do Rosário".

E ainda:

"Enquanto Marta fala, Sebastiāo vai sendo iluminado e os irmãos vão desaparecendo. As paredes ficam transparentes, revelando o esplendor da irmandade reunida na nave da igreja. Todo o palco fica dourado" (id., ibid., p. 40).

"Slides de milharais e arrozais batidos pelo vento são projetados sobre o palco, colorindoo de verde" (id., ibid.).

Lembrando-se, aqui, um recurso já usado em Rasto atrás e em $O$ sumidouro e que remete ao estilo de Piscator.

A peça é bastante fragmentada, reflexo da fragmentação e hierarquização da própria sociedade brasileira colonial. Vê-se, portanto, que a estrutura dramática e cênica harmoniza-se com seu tema e com a perspectiva crítica imprimida pelo autor, não podendo ser facilmente dissociados forma e conteúdo.

O mesmo poderia ser dito de $O$ sumidouro, onde ainda acrescenta-se o elemento confessional (e metalingüístico), já que quase toda a peça é a projeção da mente do protagonista, o dramaturgo Vicente.

O último texto escolhido é Milagre na cela (Andrade, 1977), peça que não integra o ciclo Marta, e que é a mais trabalhada, em termos cênicos, dentre as peças "avulsas". $\mathrm{O}$ texto tem uma forma convencional, de dois atos, sem marcação do número de cenas.

São três os ambientes no drama: a prisão, a casa do delegado e o convento. O último é o mais simples, não apresentando nem mesmo uma breve descrição. É invocado rapidamente pela rubrica:

"Joana deita-se no catre. Desaparece a cena. Ilumina-se a sala do convento, onde meia-dúzia de freiras estão reunidas" (id., ibid., p. 23).

Como se vê, todo e qualquer detalhamento que seja necessário é deixado por conta do diretor do espetáculo. Até mesmo a participação dos personagens na cena é vaga. Pede-se meia-dúzia de freiras, sem muita precisão. Depois, nos diálogos, não há indicação de quais freiras, dentre essa meia-dúzia, deve falar. Aqui também essas marcações são deixadas ao responsável pela montagem. Este fato justifica-se do ponto de vista dramático já que, a não ser a madre, nenhuma das religiosas tem um destaque maior, atuando como um coro.

No que diz respeito ao cenário relativo à casa do delegado, a imprecisão das rubricas não é tão grande. Da mesma forma, é muito maior a preocupação com a apresentaçáo do personagem (o delegado) e seu conflito psicológico. Portanto, há uma equivalência na relação entre descrição do espaço e importância da trama na economia da peça. Assim, para criar o espaço da vida cotidiana do delegado torturador, o autor apresenta o seu universo doméstico (sempre fazendo a transferência de um ambiente a outro pelo jogo de luzes).

"Jupira se volta no catre. Joana se aproxima da parede e começa a ler o que está escrito nela. Desaparece a cena quando se ilumina a sala da casa de Daniel. A sala é bem arrumada, revelando em tudo um ambiente essencialmente familiar. Daniel está sentado à mesa, escrevendo. Marina entra com um vaso de flores e vai colocar em cima de um móvel. Enquanto faz isto, observa Daniel, revelando ter alguma coisa a dizer. Daniel parece ser outro homem, completamente diferente do que aparece na prisão. A atmosfera na sala é de paz e amor" (id., ibid., p. 29).

$\mathrm{O}$ contraste que o autor procurou criar entre $\mathrm{o}$ ambiente "familiar", de "paz e amor", só faz crescer a tensão com a condição de torturador do personagem. Foi, aliás, a apresentação desse lado humano de Daniel um dos pontos que causou maior polêmica quando da publicação da peça. A maior atenção dada, em termos de descrição do ambiente e indicação de possíveis significados simbólicos que dele se poderiam extrair, fica reservada para a prisão. Esta sim é o 
centro de todo o conflito. Há um detalhamento à parte para o ambiente da cadeia, logo antes do início das cenas:

"Salas, corredores e celas de uma prisão que lembra uma construção medieval. Quando inteiramente iluminado, assemelha-se a uma catedral. Ao longo da peça ouvem-se sons de sinos, buzinas, barulho de pessoas praticando o karatê, latidos de cães policiais e gritos indistintos. Em todos os lugares, menos nas celas, há sempre um crucifixo. As paredes da cela de Joana são inteiramente rabiscadas, mas não se distinguem as palavras, a não ser chegando muito perto. Aparecem ainda a sala da casa de Daniel e a do convento" (id., ibid., p. 14).

É um cenário camaleônico, mutável de acordo com a metáfora que o autor deseja imprimir em determinado momento do texto. Além da descrição, concentrada nessa rubrica inicial, há outras que vão completando o universo simbólico do drama, como por exemplo:

"CENA - Quando se abre o pano, apenas a sala do carcereiro está iluminada. Ele assiste televisão, enquanto lê uma revistinha de quadrinhos. A televisão deve ficar ligada durante todo o desenrolar de peça. Logo depois entra Daniel" (id., ibid., p. 15).

Veja-se também a questão das palavras inscritas na parede da cela de Joana. Elas devem ser ilegíveis para o público, mesmo para a protagonista só é possível lê-las quando se aproxima da parede. Mas o fato de Jorge Andrade ter usado de um recurso visual para fazer uma citação, mesmo que de um "autor desconhecido", dá uma ressonância maior ao fato - que se faz presente a cada vez que a cela se ilumina - do que se se tratasse de um texto lido, ou dito, pontualmente, durante a peça. A escrita torna-se um ícone poderoso. Dá, inclusive, uma dimensão metalingüística à peça. Outro elemento constantemente presente, sem que se faça uma referência verbal a ele, é o crucifixo, encontrado em quase todos os ambientes do cenário.
Talvez seja neste texto que Jorge Andrade tenha trabalhado mais intensamente os recursos sonoros. Ele já o fizera antes, em outras peças. Ruídos de trem, relógio, flauta, etc. sempre tiveram uma carga simbólica importante em suas peças. Em Milagre na cela, ele utiliza outros tipos de ruídos, agregando-os, simultaneamente, a um gestual e um comportamento cênico que contribuem para criar um clima de irrealidade em determinadas cenas, como por exemplo:

"De repente, Daniel faz um sinal. Instantaneamente, os homens começam a simular uma luta de Karatê em volta de Joana. Eles saltam no ar, jogando os pés e punhos na direção do rosto de Joana, ao mesmo tempo em que gritam. Os pés e os punhos fechados passam a um palmo do rosto e do corpo de Joana. Esta, embora temerosa, mantém-se firme na cadeira. A luta simulada se transforma num bailado sinistro. $O$ rosto dos homens são máscaras odientas. Seus gritos, sons primitivos. Daniel olha para eles como se fossem feras domesticadas. De repente, os homens param e voltam aos seus lugares, estáticos. Olham Joana com um desejo assassino, como se fossem cabeças da mesma hidra, do mesmo dragão. Daniel sorri” (id., ibid., p. 37).

"Com relutância Miguel segue Cícero. Antes de sair, Miguel se volta e olha na direção de Joana, ansioso. Ilumina-se a sala do interrogatório. Os homens continuam em volta da sala, parados, imóveis. Daniel é o único que se movimenta. Porém, os movimentos de cabeça e de braços de Daniel são reproduzidos exatamente iguais pelos seis homens que o rodeiam. É como se fosse apenas um corpo comandando sete cabeças e quatorze braços. Os movimentos de braços são lentos lembrando tentáculos que se agitam” (id., ibid., p. 51).

"Cícero sorri e sai. Ilumina-se a cela de Joana. Ela está fazendo ginástica com energia dobrada. Logo em seguida, ilumina-se a sala do interrogatório. Daniel está sozinho no meio 
da sala e responde às VOZES que vêm de todos os lados. Vozes de homens, mulheres e crianças. Daniel parece acuado. Durante a cena ouvem-se, indistintamente, passos e conversas de muitas pessoas. Esses ruidos devem fazer fundo à cena e vão num crescendo até abafar a voz de Daniel. Os sons dos lutadores de karatê e os latidos dos cães policiais dominam tudo no final. Joana acompanha a cena fazendo ginástica e sorrindo com determinação" (id., ibid., p. 79).

Segue-se toda uma cena em que Daniel dialoga com "Vozes". Na cena final:

"Joana se volta com resolução e sai. Ela pára no meio das celas e abre os braços numa entrega total. À medida que começa a cantar, uma luz estranha ilumina o cenário. $O$ ambiente parece milagroso, cheio de mistérios. Pouco a pouco, vozes que vêm de outras celas, acompanham Joana. A música se transforma num samba com ritmo intenso. Jupira entra numa dança frenética, acompanhada por Joana. As duas são perfeitas passistas. Sombras dançando surgem em todos os cantos. $O$ coro se eleva cada vez mais, até que se fecha a cortina" (id., ibid., p. 93).

Estas cenas mesclam-se a cenas mais naturalistas que compõem a maior parte do drama. Em comparação com as peças anteriores de Jorge Andrade, surge a diferença de que os sons ou o comportamento não naturalista dos personagens extrapola a representação de uma projeção mental ( $O$ sumidouro) ou da memória (Rasto atrás e As confrarias). O épico impregna o "real" da trama dramática, quebrando os limites entre o universo pessoal de um personagem para transformar-se em realidade ficcional.

Por outro lado, Milagre na cela também conserva outras ligações com as obras anteriores de Jorge Andrade. Veja-se, como exemplo, a escolha dos nomes para os personagens (tão relevante no mundo jorgeandradiano). Tem-se Jupira, a eterna prostituta, e Gabriel (nome de anjo, como em Pedreira das almas). É certo que o dramaturgo conservou-se dentro dos limites da dramaturgia de caráter épico, com ecos expressionistas, que já haviam sido trilhados por outros dramaturgos, alguns deles, aliás, declaradamente admirados por Jorge: Arthur Miller, O'Neill e Brecht. Como esses mesmos autores, na obra do brasileiro, a relação entre texto dialogado e rubrica guarda uma hierarquia que valoriza, sobretudo, o aspecto textual. Jorge Andrade é um falador. Não há, no entanto, como negar que muito da estrutura das peças que escreveu está contida nas rubricas. Não segui-las seria inviabilizar sua obra. Portanto, justifica-se que se chegue a determinadas conclusões a respeito de seu trabalho a partir da análise didascálica.

Partindo do que foi dito até aqui, podese constatar, sempre através das rubricas, que houve uma crescente sofisticação nos textos do autor e que essa alteração se deu, sobretudo, na maior elaboração dos aspectos cênicos das peças. Com o passar dos anos, Jorge Andrade foi abandonando as rubricas puramente melódicas e expandindo aquelas que se referiam ao aspecto espetacular do drama. Cada vez mais, foi pensando como um encenador, além de autor. Contudo, não se transformou num ciumento de sua obra. Em diferentes ocasiōes, deixou claro (explicitamente ou por omissão) que seria necessária a interferência de uma segunda pessoa para completar seu trabalho. Generoso, sabe-se também que aprendeu a aceitar as intervençôes dos diversos diretores que encenaram seus textos, tendo mesmo modificado alguns trechos a partir das montagens.

Através da breve análise dos tipos de rubricas que foram usadas por Jorge Andrade feita aqui, podemos compreender que muitos dos procedimentos da moderna dramaturgia estão contidas nessa escrita, tão própria ao texto dramático. Prova-se também que o próprio texto teatral, através do estudo das rubricas, pode fornecer elementos para a análise dos aspectos cênicos de determinado autor, sem que se faça necessário assistir a uma montagem. Se tal fos- 
se estritamente necessário, Jorge Andrade seria prejudicado, visto que, infelizmente, até agora, o teatro nacional ainda deve a esse autor a montagem de seus mais complexos e melhores textos.

\section{$\longrightarrow$ \\ Referências bibliográficas}

ANDRADE, J. Marta, a Árvore e o Relógio. São Paulo, Perspectiva, 1970. . Milagre na cela. São Paulo, Paz e Terra, 1977.

FRAGA, E. Nelson Rodrigues expressionista. São Paulo, Ateliê Editorial, 1998. 